\title{
The impact of child-targeted dietary counseling of parents on food (milk) preferences of preschool-aged children in the STRIP project
}

\author{
By Hanna Lagström, Ritva Seppänen, Eero Jokinen, \\ Mari Salminen and Olli Simell \\ Received July 5, 2000; Revised April 9; Accepted May 282001
}

\begin{abstract}
Objective: To evaluate the food choices of the 6.5-year-old children in the STRIP trial.

Design: 6.5-year-old children $(\mathrm{n}=102)$ were randomly selected for this study from participants $(\mathrm{n}=1062)$ in the Special Turku Coronary Risk Factor Intervention Project (STRIP), which began at the child's age of 6 months and is a prospective long-term coronary heart disease prevention trial. The children and their families $(n=1054)$ were randomized in the main project to form an intervention and a control group. The intervention families were repeatedly counseled to reduce child's intake of saturated fat and cholesterol. Using 50 pictures of individual food items, the children were asked to pick out their this morning's, yesterday's, last weekend's breakfast, the breakfast she/he would like to have, the breakfast the child thought the parents would like him/ her to have, and a healthy breakfast.

Results: More intervention than control children ( $\mathrm{n}=98$ in the final analysis) chose skim milk in all the questions. The different bread spread choices of the intervention and the control children were always very similar. The children in both groups explained the meaning of a "healthy breakfast" most frequently (45-47\% of answers) as a meal that makes one feel good and prevents sickness. Conclusions: Our data suggest that in the STRIP trial, after repeated child-targeted dietary counseling of the parents, the intervention children at the age of 6.5 years pretty well accepted skim milk for breakfast. It was only for milk that the extensive parental counseling seemed to have had an effect. There was no difference between groups with respect to the choice of fruit and vegetables.

Keywords: Fat, food choice, intervention, milk, preschool children
\end{abstract}

\begin{abstract}
Introduction
Coronary heart disease (CHD) mortality is a major health problem in all western countries (1). The first vascular changes in this disease are already visible in childhood, even though the symptoms usually appear later in life (2). Thus dietary counseling of parents regarding the child's nutrition may influence CHD risk later in life through permanent modification of the child's eating habits and preferences, although food habits are known to be unstable (3).

When children are allowed to choose their meal freely from healthy foods and from foods high in fat, salt and sugar, they tend to choose salty, sugary and fatty foods (5). School children between the ages of 10 and 16 years mainly choose their breakfast according to taste preferences, availability and previous habits if given a free choice (6). Children between the ages of 5 and 18 years in the United States also knew of the health effects of dietary fat and fiber, but their knowledge of the fat and fiber content of specific foods was limited (7).

The main aim of the randomized, prospective Special Turku Coronary Risk Factor Intervention Project for children (STRIP) is to reduce children's exposure to known environmental atherosclerosis risk factors by giving regular dietary counseling. The intervention used in the STRIP project has resulted in
\end{abstract}

Hanna Lagström ${ }^{1,2}, \mathrm{PhD}$, Ritva Seppänen ${ }^{3}, \mathrm{DSc}_{\text {, Eero Jokinen }}^{4}, \mathrm{MD}$, Mari Salminen $^{1}$, MSc, Olli Simell ${ }^{5}$, MD

${ }^{1}$ Research Centre of Applied and Preventive Cardiovascular Medicine,

${ }^{2}$ Dept of Biochemistry and Food Chemistry and Dept of 5Pediatrics, University of Turku, ${ }^{3}$ The Research and Development Unit of the Social Insurance Institution, Turku, ${ }^{4}$ Hospital for Children and Adolescents, University of Helsinki, Helsinki, Finland

Correspondence: Hanna Lagström, Dept of Biochemistry and Food Chemistry,

University of Turku, Vatselankatu 2, FIN-20014 Turku, Finland.

E-mail: hanna.lagstrom@utu.fi markedly decreased intakes of saturated fatty acids and cholesterol during the first four years of life. Other nutrients complied with current recommendations, except for vitamin D and iron (8). In fact, children in the intervention group used more skim milk and vegetable margarine between the ages of one and five years compared to the children in the control group (9). We have also shown that the serum cholesterol concentrations of the STRIP intervention children are lower than those of the control children $(10,11)$.

The dietary counseling in the STRIP trial focuses on the child's diet and has so far been addressed to the parents. In practice, nutrition education for preschool age children is usually delivered via parents, but the impact of such child-oriented nutrition counseling of parents on the food choices made by their children has not been studied in detail. Due to the considerable effect of counseling on the food consumption and nutrient intakes of children under school age, and since the children take a more active role in food selection during the preschool period, it is important to evaluate the impact of the given dietary counseling on the food choices of preschool-aged children. The method used to identify existing food habits of children is based on stacking boxes with food pictures, used for school children aged 10,13 and 16 years (6).

In this study the method was used to evaluate the food choices of the 6.5-year-old intervention and control children in the STRIP trial.

\section{Methods}

\section{Design and subjects}

The design of the STRIP project (Special Turku Coronary Risk Factor Intervention Project for children) has been described $(10,11)$. Briefly, STRIP is a prospective randomized long-term atherosclerosis prevention trial. Families $(n=1054 ; 1062$ infants $)$ 


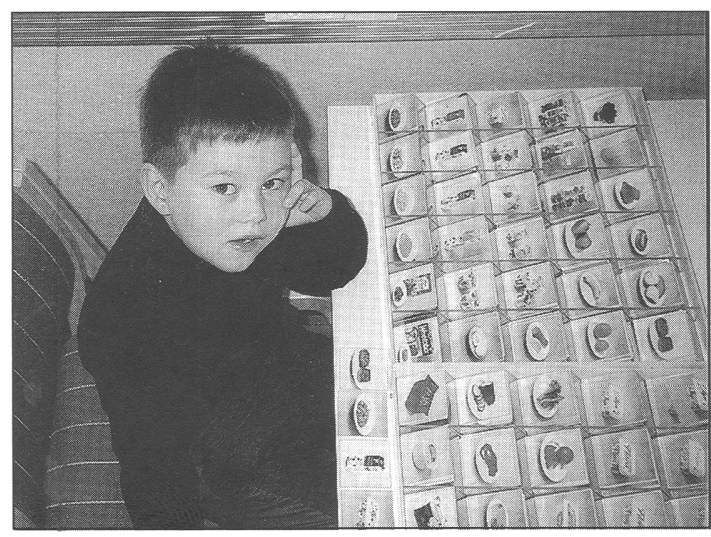

Figure 1.A child selects his breakfast from a panel of 50 food pictures.

were recruited for the trial at child's age of 5 months at the wellbaby clinics in the city of Turku, Finland, and were first seen by the study group at the child's age of 6 months. Of the eligible age cohort, $56.5 \%$ decided to participate, and the children and their families were randomized to form an intervention group $(n=540$; 3 twinpairs) and a control group ( $n=522 ; 5$ twinpairs). For practical reasons, twins were randomized together.

This study was carried out between April and September 1997, when the age of each child studied was 6.5 years. One hundred and two children, comprising equal numbers of intervention and control children, and of girls and boys, were randomly selected for this study from participants in the main project. Ninety-eight children (49 intervention and 49 control children) were included in the final analysis, as four children were unwilling to complete the test.

The STRIP project has been approved by the Joint Ethics Committee of the Turku University and the Turku University Central Hospital. Informed consent was obtained from all parents/guardians.

\section{Counseling}

The intervention families met with a pediatrician, and a nutritionist and nurse at 1 to 3 -month intervals until the age of 2 years, and after that twice a year. The control families met the same team twice yearly from the beginning of the trial. The intervention families were counseled to reduce the child's intake of saturated fat and cholesterol, but to supply adequate amounts of energy as described below in detail (12). The individualized counseling focused mainly on the child's diet, and it was based on the previous food habits of the child and his/her family. During the first visit, the family's diet was assessed by a nutritionist using 24-hour dietary recall. The intervention group families then received individualized counseling aiming at a fat intake of $30 \mathrm{E} \%$ to $35 \mathrm{E} \%$ for the child before 3 years of age, after which the fat content of the diet recommended in the counseling was tapered to $30 \mathrm{E} \%$. The purpose was not to reduce fat intake before the age of 13 months. The ratio of polyunsaturated $(\mathrm{P})$, monounsaturated $(\mathrm{M})$, and -saturated $(\mathrm{S})$ fatty acids was planned to be $1: 1: 1$. In practical counseling, the goal was a ratio of $(\mathrm{P}+\mathrm{M}): \mathrm{S}=2: 1$. The principles of the recommended intervention diet were reviewed at each visit, practical food recommendations were given, and the diet was adjusted according to the age of the child. Each visit to the nutritionist lasted about half an hour and the counseling was individual, i.e. the main aims of dietary counseling were similar for all the intervention families, but the implementation was unique.

After infancy, the parents of the intervention children were advised to use skim milk as the milk source for their children and to add daily 2 to 3 teaspoons of vegetable oil or soft margarine to the food until the age of 2 years to compensate for the missing fat in their recommended daily milk portion. The aim was to maintain fat intake at the same level as in children who drank milk with $1.9 \%$ fat (medium-fat milk; milk with $1.5 \%$ fat from May 1995). The use of oil or soft margarine instead of butter in food preparation was encouraged. Detailed suggestions were made to replace products containing large amounts of saturated fat with products containing mono- and polyunsaturated fatty acids instead. The use of leaner meat products, low-fat cheese, and ice-cream with vegetable fat, combined with ample use of vegetables was advised. Fish was recommended as one of the main meals twice a week after the age of 1 year. No foods were prohibited. A fixed diet was never prescribed but during each visit suggestions were made for small changes steering the diet towards an optimal composition.

Dietary issues were discussed with the control families only in a general way according to the practice of Finnish child health centers, and no detailed suggestions on the use on fat were made to the families of the control children. The use of cow's milk with at least $1.9 \%$ fat was recommended after the age of 12 months, and no other suggestions concerning the type of fat in the diet were given.

\section{Foods}

To illustrate the food choices of children, breakfast was chosen as the meal for the study, because a typical Finnish breakfast contains several food items on which the counseling in the present study primarily focused. Such foods are milk products, cheese, meat products, and margarine or butter on bread. Color photographs of 50 different food items were available in two special food picture stands. Among these were four types of milk with different fat contents, seven types of processed sour milk (yogurts and 'Nordic ropy sour milk products'="viili") with different fat contents, 15 types of bread fat (margarine and butter), six types of cheese and four types of meat products (sausages, cold cuts). Also five types of breakfast cereals, one oatmeal porridge, four different types of bread, and ten different vegetables or fruits were included in the photographs. During the trial, the children's food consumption was evaluated using food records kept at 5 to 12-month intervals. All the foodstuffs in the pictures were thus those known to be the most commonly used by children.

\section{Test situation and data collection}

The test was first described to the child and the parents together. Then only the child remained in the test room with a nutritionist and was told that he or she would be asked questions about his or her breakfast meals. The children were then asked to select food items from the food picture stands according to six questions:

1) Collect the breakfast you had this (study) morning (later called this morning's breakfast)

2) Collect the breakfast you had yesterday morning (yesterday's breakfast)

3) Collect the breakfast you had last weekend (weekend breakfast)

4) Collect the breakfast you would like to eat (breakfast I like)

5) Collect the breakfast your parents would like you to eat (parent-preferred breakfast)

6) Collect a healthy breakfast (healthy breakfast)

After six different choices, the children were asked to collect this morning's breakfast once again in order to analyze how persistent the child's food choices in this test situation were.

The children selected their breakfast choices freely from a panel of 50 pictures described (Figure 1). There were 10 sets of 
Table 1. Percentages (number) of milk choices of different questions of all children in the intervention (I; $n=49)$ or control (C; $n=49)$ group. Fisher's exact test was used for comparing choices between children in the intervention and in the control group.

\begin{tabular}{|c|c|c|c|c|c|c|c|c|c|c|c|c|c|c|c|}
\hline & \multicolumn{3}{|c|}{ Full milk } & \multicolumn{3}{|c|}{ Milk with $1.5 \%$ fat } & \multicolumn{3}{|c|}{ Milk with $1 \%$ fat } & \multicolumn{3}{|c|}{ Skim milk } & \multicolumn{3}{|c|}{ No milk chosen } \\
\hline & I & $\mathrm{C}$ & $\mathrm{P}^{1}$ & I & $\mathrm{C}$ & $\mathrm{P}^{1}$ & $\mathrm{I}$ & $\mathrm{C}$ & $\mathrm{P}^{1}$ & I & $\mathrm{C}$ & $\mathrm{P}^{1}$ & $\mathrm{I}$ & $\mathrm{C}$ & $\mathrm{P}^{1}$ \\
\hline & $\%$ & $\%$ & & $\%$ & $\%$ & & $\%$ & $\%$ & & $\%$ & $\%$ & & $\%$ & $\%$ & \\
\hline & $n$ & $n$ & & $n$ & $n$ & & $n$ & $n$ & & $n$ & $n$ & & $n$ & $n$ & \\
\hline \multirow[t]{2}{*}{ This morning's breakfast } & - & - & ns & 2.0 & 22.5 & $* * *$ & 8.2 & 14.3 & ns & 46.9 & 36.7 & ns & 42.9 & 26.5 & ns \\
\hline & 0 & 0 & & 1 & 11 & & 4 & 7 & & 23 & 18 & & 21 & 13 & \\
\hline \multirow[t]{2}{*}{ Yesterday's breakfast } & 2.0 & - & ns & 4.1 & 14.3 & ns & 8.2 & 24.5 & $*$ & 55.1 & 28.6 & $* *$ & 30.6 & 32.7 & ns \\
\hline & 1 & 0 & & 2 & 7 & & 4 & 12 & & 27 & 14 & & 15 & 16 & \\
\hline \multirow[t]{2}{*}{ Weekend breakfast } & - & 2.0 & ns & - & 16.3 & $* * *$ & 8.2 & 22.5 & ns & 53.1 & 30.6 & $*$ & 38.8 & 28.6 & ns \\
\hline & 0 & 1 & & 0 & 8 & & 4 & 11 & & 26 & 15 & & 19 & 14 & \\
\hline \multirow[t]{2}{*}{ Breakfast I like } & 2.0 & 2.0 & $\mathrm{~ns}$ & 2.0 & 14.3 & ns & 8.2 & 20.4 & ns & 53.1 & 30.6 & $*$ & 36.7 & 34.7 & ns \\
\hline & 1 & 1 & & 1 & 7 & & 4 & 10 & & 26 & 15 & & 18 & 17 & \\
\hline \multirow[t]{2}{*}{ Parents-preferred breakfast } & - & 4.1 & ns & 2.0 & 16.3 & $*$ & 6.1 & 16.3 & ns & 73.5 & 42.9 & $* * *$ & 18.4 & 20.4 & ns \\
\hline & 0 & 2 & & 1 & 8 & & 3 & 8 & & 36 & 21 & & 9 & 10 & \\
\hline \multirow[t]{2}{*}{ Healthy breakfast } & - & - & ns & 4.1 & 10.2 & ns & 10.2 & 14.3 & $\mathrm{~ns}$ & 50.0 & 32.7 & $\mathrm{~ns}$ & 36.7 & 42.9 & ns \\
\hline & 0 & 0 & & 2 & 5 & & 5 & 7 & & 24 & 16 & & 18 & 21 & \\
\hline
\end{tabular}

$1 * * *=\mathrm{p}<0.001, * *=\mathrm{p}<0.01, *=\mathrm{p}<0.05, \mathrm{~ns}=$ not significant

each picture and after each answer the used pictures were removed from the table. When children were asked to collect a healthy breakfast, they were also asked to explain what they think a "healthy breakfast" means. Each interview lasted about 15 minutes and was carried out by one nutritionist at a time (the investigator and one other). During these interviews of children, their parents were given dietary counseling by another nutritionist. During the visit with a nutritionist, the parents were asked details about the milk and bread spread the child used at home. In the following analysis of the test results of children, major emphasis was placed on milk and bread spread choices since these foods were key targets in the dietary counseling given in STRIP trial.

\section{Statistical analysis}

Fisher's exact test was used for comparing differences in food choices between the intervention and control children. Both genders were analyzed together, because there were no differences between the answers given by the boys and those of the girls. The McNemar test was used for measuring agreement between children's and parents' answers; the Simple kappa is scaled $[0,1]$ and 1 means total agreement. For statistical computation, BMDP (version 1990; BMDP Statistical Software, Los Angeles, CA) and SAS (version 6.08; SAS Institute, Cary, NC) statistical program packages were used. Differences were considered significant at $\mathrm{p}<0.05$.

\section{Results}

Fifty-three of 98 children $(54.1 \%$ ) selected exactly the same food pictures (selected food pictures mean 3.4 \pm 1.1 ) in the two identical questions regarding this morning's breakfast. Forty-five children show some differences on the two separate questions concerning this morning's breakfast (selected food pictures $3.8 \pm 1.2$ ). Thirty-two of these 45 children had a milk and/or bread spread group included in their answers although there were differences in these choices (for example the milk choice in question one was skim milk and in question eight milk with $1 \%$ fat). Only eight children had a milk or bread spread choice in one of the questions on this morning's breakfast, but not in the other one (in the case of three children both the milk and bread spread pictures are missing). However, 19 children have exactly same number of selected pictures in these two different questions, nine

Table 2. Percentages and numbers $(n)$ of bread fat choices of different questions of all children in the intervention $(I ; n=49)$ or control $(C ; n=49)$ group. Fisher's exact test was used for comparing choices between children in the intervention and in the control group.

\begin{tabular}{|c|c|c|c|c|c|c|c|c|c|c|c|c|c|c|c|}
\hline & \multicolumn{3}{|c|}{ Butter } & \multicolumn{3}{|c|}{ Margarine $80 \%$} & \multicolumn{3}{|c|}{ Margarine $60 \%$} & \multicolumn{3}{|c|}{ Margarine $40 \%$} & \multicolumn{3}{|c|}{ No spread chosen } \\
\hline & I & $\mathrm{C}$ & $\mathrm{P}^{1}$ & I & C & $\mathrm{P}^{1}$ & I & $\mathrm{C}$ & $\mathrm{P}^{1}$ & I & $\mathrm{C}$ & $\mathrm{P}^{1}$ & I & $\mathrm{C}$ & $\mathrm{P}^{1}$ \\
\hline & $\%$ & $\%$ & & $\%$ & $\%$ & & $\%$ & $\%$ & & $\%$ & $\%$ & & $\%$ & $\%$ & \\
\hline & $n$ & $n$ & & $n$ & $n$ & & $n$ & $n$ & & $n$ & $n$ & & $n$ & $n$ & \\
\hline \multirow[t]{2}{*}{ This morning's breakfast } & 4.1 & 6.1 & ns & 34.7 & 26.5 & ns & 8.2 & 4.1 & ns & 2.0 & 2.0 & ns & 51.0 & 61.2 & ns \\
\hline & 2 & 3 & & 17 & 13 & & 4 & 2 & & 1 & 1 & & 25 & 30 & \\
\hline \multirow[t]{2}{*}{ Yesterday's breakfast } & 4.1 & 10.2 & ns & 34.7 & 30.6 & ns & 14.3 & 4.1 & ns & 4.1 & 2.0 & ns & 42.9 & 55.1 & ns \\
\hline & 2 & 5 & & 17 & 15 & & 7 & 2 & & 2 & 1 & & 21 & 26 & \\
\hline \multirow[t]{2}{*}{ Weekend breakfast } & 6.1 & 8.2 & $\mathrm{~ns}$ & 34.7 & 38.8 & ns & 14.3 & 12.2 & ns & 4.1 & 6.1 & ns & 40.8 & 34.7 & ns \\
\hline & 3 & 4 & & 17 & 19 & & 7 & 6 & & 2 & 3 & & 20 & 17 & \\
\hline \multirow[t]{2}{*}{ Breakfast I like } & 6.1 & 10.2 & ns & 30.6 & 14.3 & ns & 20.4 & 8.2 & ns & - & 2.0 & ns & 42.9 & 51.0 & ns \\
\hline & 3 & 5 & & 15 & 7 & & 10 & 4 & & 0 & 1 & & 21 & 25 & \\
\hline \multirow[t]{2}{*}{ Parents-preferred breakfast } & 4.1 & 8.2 & ns & 38.8 & 40.8 & ns & 16.3 & 10.2 & ns & 4.1 & 6.1 & ns & 36.7 & 34.7 & ns \\
\hline & 2 & 4 & & 19 & 20 & & 8 & 5 & & 2 & 3 & & 18 & 17 & \\
\hline \multirow[t]{2}{*}{ Healthy breakfast } & 2.0 & 6.1 & ns & 18.4 & 16.3 & ns & 12.2 & 6.1 & ns & - & 4.1 & ns & 67.3 & 37.3 & ns \\
\hline & 1 & 3 & & 9 & 8 & & 6 & 3 & & 0 & 2 & & 33 & 33 & \\
\hline
\end{tabular}

$1 * * *=\mathrm{p}<0.001, * *=\mathrm{p}<0.01, *=\mathrm{p}<0.05, \mathrm{~ns}=$ not significant 
Table 3. The number of 6.5-year-old intervention children and control children $(n=98)$, selecting fruit and vegetable for different types of breakfasts.

\begin{tabular}{lccc}
\hline Children & Intervention & Control & $\mathrm{P}^{1}$ \\
\hline This morning's breakfast & 23 & 18 & $\mathrm{~ns}$ \\
Yesterday's breakfast & 30 & 21 & $\mathrm{~ns}$ \\
Weekend breakfast & 30 & 25 & $\mathrm{~ns}$ \\
Breakfast I like & 38 & 32 & $\mathrm{~ns}$ \\
Parents-preferred breakfast & 25 & 20 & $\mathrm{~ns}$ \\
Healthy breakfast & 38 & 38 & $\mathrm{~ns}$ \\
\end{tabular}

$1 * * *=\mathrm{p}<0.001, * *=\mathrm{p}<0.01, *=\mathrm{p}<0.05, \mathrm{~ns}=$ not significant

Table 4. The number of 6.5-year-old intervention children and control children ( $n=98)$ using different types of milk and bread spread at home as reported by parents.

\begin{tabular}{lccc}
\hline Children & Intervention & Control & $\mathrm{P}^{1}$ \\
\hline Milk type at home & & & \\
Milk 1.5\% fat & 0 & 14 & $* * *$ \\
Milk 1.0\% fat & 5 & 10 & $\mathrm{~ns}$ \\
Skim milk & 43 & 24 & $* * *$ \\
No milk & 1 & 1 & $* * *$ \\
Bread spread at home & & & \\
Margarine 40\% fat & 2 & 6 & $\mathrm{~ns}$ \\
Margarine 60\% fat & 18 & 7 & $\mathrm{~ns}$ \\
Margarine $80 \%$ fat & 28 & 26 & $* * *$ \\
Butter & 1 & 10 & \\
& & &
\end{tabular}

$1 * * *=\mathrm{p}<0.001, * *=\mathrm{p}<0.01, *=\mathrm{p}<0.05, \mathrm{~ns}=$ not significant

Table 5. A comparison at group level of the milk type used at home as reported by parents with the answers of children on "this morning's breakfast", yesterday's breakfast and the parent-preferred breakfast-in the intervention $(n=49)$ and in the control group $(n=49)$.

$\begin{array}{lcccc}\text { Milk } & \text { Full } & \begin{array}{c}1.5 \% \\ \text { fat }\end{array} & \begin{array}{c}1.0 \% \\ \text { fat }\end{array} & \text { Skim }\end{array}$

\section{Intervention group}

Parents

Children: This morning's breakfast 0

Children: Yesterday's breakfast 1

Parent-preferred breakfast

$\begin{array}{llll}0 & 0 & 5 & 44 \\ 0 & 1 & 4 & 23 \\ 1 & 2 & 4 & 27 \\ 0 & 1 & 3 & 36\end{array}$

\section{Control group}

Parents

0

Children: This morning's breakfast 0

Children: Yesterday's breakfast

Parent-preferred breakfast

0

14

10

10

7

12

Table 6. The agreement of milk choice at home (parents report) and milk choice of children (the most commonly choice in different questions). Intervention and control group together $(n=95$, one child did not have milk at home, two children did not choos milk in any of various questions). McNemar test was used for used for measuring the agreement between children and parents answers. Simple kappa 0.79 .

$\begin{array}{lccc}\text { Milk choice } & \text { Full milk } & \text { Milk } & \text { Milk } \\ \text { of children } & & 1.5 \% \text { fat } & 1.0 \% \text { fat }\end{array}$ Skim milk

Milk at home

Full milk

Milk with $1.5 \%$ fat

Milk with $1.0 \%$ fat

Skim milk

0
0
0
0

0
9
2
2

0
0
11
5

0
5
2
59

children picked out more pictures in question one than in question eight (one picked five pictures more) and 14 children picked out more pictures in question eight than in question one (one to four pictures more). Usually children forgot one or two items of the break-fast eaten. Thus 25 children $(25.5 \%)$ had one missing item and $9(9.2 \%)$ had two different items in choices in the two separate questions on the study morning's breakfast. Eleven children $(11.2 \%)$ answered the two identical questions with totally different pictures.

\section{Selection of milk type and bread spread}

For "this morning's breakfast" the intervention children and the control children chose milk with $1 \%$ fat or skim milk with equal frequency, but the control children more often selected milk with $1.5 \%$ fat $(\mathrm{p}<0.001)$ (Table 1$)$. For "yesterday's breakfast" the control children more often chose milk with $1 \%$ fat than the intervention children $(\mathrm{p}<0.05)$, whereas the intervention children chose skim milk more frequently $(\mathrm{p}<0.01)$. The same trend in milk selections of the two groups of children continued when the children chose the "weekend breakfast", as more of the intervention children $(n=26)$ than of the control children $(n=15)$ chose skim milk $(\mathrm{p}<0.05)$ and eight control children but no intervention children chose milk with $1.5 \%$ fat $(\mathrm{p}<0.001)$ (Table 1$)$. For the "breakfast I like" and the "parent-preferred breakfast" the intervention children chose skim milk more often than the controls ( $p<0.05$ and $p<0.001$, respectively). Interestingly, the milk selections of the intervention and control children for the "healthy breakfast" were very similar (Table 1). The choices of the intervention and the control children for bread spread shown no differences (Table 2). Only one to two children selected whole milk in any of the different questions (Table 1).

\section{Selection of fruit and vegetables}

Very similar numbers of intervention and control children chose fruit or vegetables for their breakfasts in all questions (Table 3). For the "healthy breakfast", exactly the same number of intervention children $(n=38)$ and controls $(n=38)$ chose fruit and vegetables (Table 3 ).

\section{Milk and bread spread use at home}

The parents reported large differences in the use of different milk types by the intervention children and the control children at home (Table 4): none of the intervention children and 14 control children used milk with $1.5 \%$ fat, five intervention and 10 control children used milk with $1 \%$ fat and 43 intervention and 23 control children used skim milk ( $\mathrm{p}<0.001$ for all measurements). The parents also reported that the intervention children used margarine with $60 \%$ fat more often than the control children $(\mathrm{p}<0.05)$ and the control children used butter more often than the intervention children $(\mathrm{p}<0.001)$ (Table 4$)$. The compatibility at the group level between the parents report of the milk type use at home and the children's answers on this morning's, yesterday morning's and parents' preferred breakfast are shown in Table 5 separately for the intervention and the control group. The reliability of the milk choice within the family is analyzed by agreement between the child's most common milk choice in different questions and parent's report of the milk type use at home (Table 6). The agreement between the child's most common milk choice and his/her parents report is good; $80.6 \%$ of all child/parent pairs chose the same type of milk (Simple kappa value 0.79 ).

\section{Children's descriptions of a "healthy breakfast"}

When the children were asked what a "healthy breakfast" means, the most frequent response was that healthy food makes one feel 
good and healthy, not sick: $47 \%$ and $45 \%$ of the intervention and control children, respectively, gave this answer. Twenty percent of the intervention and control children explained that a "healthy breakfast" is equal to eating the right kinds of food, such as porridge, bread, cheese and milk. Eighteen percent of the intervention children, but only $10 \%$ of the control children thought that a healthy breakfast helps you to grow. Twelve percent of the intervention children and $18 \%$ of the control children answered that especially fruit and vegetables are healthy. A few children thought that a healthy breakfast is same as low-fat food ( $8 \%$ and $4 \%$ of the intervention and the control children, respectively) or food with lots of vitamins $(8 \%$ and $12 \%$ ). Only $5 \%$ of children in both groups mentioned dental health as a reason to favor healthy food.

\section{Discussion}

Newborns show a positive preference for sweet and a negative reaction to bitter and sour tastes and a neutral response to salty tastes (13). Other preferences appear to be learned. Preferences are a major determinant of food intake in young children (14). It seems that early experience with food and eating is crucial to the development of food acceptance patterns, both in terms of the acquisition of food preferences and the regulation of food intake $(14,15)$.

Preschool age children tend to associate the type of drink (milk or water) regularly served at a meal with those specific meals, for example if children have had water to drink at lunch in day-care center, they also like to have water with their school lunch (15). Our study clearly showed that intervention children more often chose milk with lower fat content than control children in a test situation. Availability at home is one of the main reasons for the choice of drink. It is also possible that the taste preferences of children may have developed in such a way that they prefer milk with a lower rather than a higher fat content. Taste has been found to be one of the major reasons for food choice in older children (6). On the other hand, the choice of bread spread did not differ between the intervention and the control children, but parents reported that the intervention children used margarine more often and butter less often than the control children. Nutrition counselling in the STRIP project focused on replacing products that contain large amounts of saturated fat (mainly drinking milk and other dairy products at the beginning) with products that contain smaller amounts of fat or with fats in which at least part of the saturated fat had been replaced by monounsaturated and polyun-saturated fats. The intervention succeeded in decreasing the intake of saturated fatty acids mainly by replacing them with foods low in saturated fat and high in unsaturated fat (16). The choices of alternatives to milk by the intervention and control children were very similar, possibly because of difficulties in changing a familiar product for a product with a different texture, or due to the familiarity of the milk package, without actually understanding the meaning of the differences between different type of milks.

\section{Parental involvement}

Parental involvement has an impact on children's thinking about nutrition and behavior. Anliker and colleagues (17) found that the more information parents communicated in a variety of ways (both verbal and nonverbal), the more specific it was, and the more positive the messages, the higher the children scored on a nutrition awareness test. In a study of parental influence on food selection, 53 children in a cafeteria setting were asked to select any items that they wished from a large array of options for lunch and to put these on their tray (5). Given such a free choice, the children chose items in which $25 \%$ of their calories came from food high in added sugar. When children were then told that their mothers would inspect their trays, they modified their choices to foods lower in added sugar. When mothers were actually given the trays to modify, they removed items to make the meal lower in calories, saturated fat and sodium, but they did not add any nutritious foods (5). Parents (the most important gatekeepers) have been found to play a significant role in making decisions about which foods are to be served at home $(5,15)$. On the other hand, if children are offered a variety of healthy foods they tend to regulate their energy intake well over 24-hour periods (18). A child who eats only a small breakfast most probably compensates for this low intake at lunch or at dinner. Although a child's total environment affects his or her food choices, the most influential part in developing a young child's food behavior seems to be played by the family (19-21).

\section{Do children understand concepts on health?}

In a study of 60 children aged 4 to 7 years, children could comprehend concepts such as energy, a strong heart and that a low-fat diet keeps one's heart healthy (22). They also found that an intervention involving nutrition education increased children's perception of the fact that health and nutrition are related concepts. Another study concluded that children were able, upon instruction using cards that displayed pictures of foods, their name and color-coded bar graphs for vitamins $\mathrm{A}$ and $\mathrm{C}$, iron, and calcium, to develop some understanding of the concepts of nutritive value, nutrient function, and the impact of nutrition on health (23). In a study of children from preschool to 12 years of age, when the children were asked "What do you think you should eat if someone told you to eat a variety of foods", the most common response of younger children from kindergarten to 8 years of age was to list food items (24). When children were asked the meaning of a "healthy breakfast" in our study both the intervention and the control children also listed food items. Younger children have some difficulties in naming high-fat foods, but they seemed to associate a low-fat diet with foods to be avoided and they named desserts, sweets, whole milk, french fries or pizza (24). Only few children in our study mentioned a low fat-diet when they explained a "healthy breakfast", none of the children, either in the intervention group or in the control group, mentioned the type of fat although that was the main goal of the dietary counseling given in the course of the STRIP trial. Rather many children did not choose milk for a healthy breakfast. One explanation might be that milk is a very common food stuff for children, and almost all children in STRIP drink milk daily (unpublished data). In fact children might not even think of milk as a healthy food. Instead children answered the question about a healthy breakfast by listing fruit and vegetables. The preschool age children in our study freely used terms such as healthy food, feeling good, vitamins, calcium, strong bones, and healthy teeth when they explained the meaning of a healthy breakfast, although these children may not fully understand the reasoning behind their choices or meanings of all words they used. Many of the study children mentioned in their explanations of a "healthy breakfast" that mother or father had told them about these matters. In the study of young children, they understood the general relationship between food choices, exercise, body fat and health, and they were also able to name foods high in fat, sugar and salt (25).

\section{Other factors affecting food choices}

Several factors affect food choices in individuals, for example cultural aspects, the availability of food, individual preferences, information, and knowledge. The experiences of food play a major role in the food choices of children, and in children's food acceptance patterns (26). In addition, the social context and the physiological consequences of eating have systematic effects on 
the development of preferences. Indeed, parents act as important role models for their children, also in health education that aims at changing the family's attitudes and habits with a view to improving health behavior (27). The results of the Framingham Children's study (28) confirmed that parents' dietary habits have an impact on the nutrient intake of their preschool children. In most families similarities in nutrient intake between children and parents indicated that parents' choices influence those of the child, and not vice versa, because parents provide the majority of the food when the child is at preschool age, and to some extent control what the child eats (28).

In our nutritional intervention, a fixed diet was never set; instead the counselling encouraged the families to make small changes that were based on each family's individual goals. It is obvious that most parents did not considered it necessary to communicate nutritional issues discussed at the counselling sessions to the child, but rather tended to rely on observational learning. This could be one reason for the inconsistency between the parents' reports on the milk used at home and the children's choice on various questions. One explanation could also be that the children might have their breakfast or other meals in different places: at home or at the day care center, or for example with grand parents, and in these places children might have had other milk available than at home.

\section{ACKNOWLEDGEMENTS}

This study was supported by grants from the Ministry of Social Affairs and Health, the Yrjö Jahnsson Foundation, the Finnish Cultural Fund, the Mannerheim League for Child Welfare, the Finnish Cardiac Research Foundation, the Academy of Finland, the Juho Vainio Foundation, the Signe and Ane Gyllenberg Foundation, the Turku University Foundation, Chymos Ltd, the Raisio Group, and Van den Bergh Foods Company.

\section{REFERENCES}

1. Henderson A: Coronary heart disease: overview. Lancet 1996;348(suppl):S1-4.

2. Pesonen E, Norio R, Hirvonen J et al: Intimal thickening in the coronary arteries of infants and children as an indicator of risk factors for coronary heart disease. Eur Heart J 1990;11 (suppl E):53-60.

3. Casey R, Rozin P: Changing children's food preferences: parent opinions. Appetite 1989;12:171-82.

4. Kelder SH, Perry CL, Klepp KI, Lylte LL: Longitudal tracking of adolescent smoking, physi-cal activity, and food behaviors. Am J Publ Helath 1994;84:1121-6.

5. Klesges RC, Stein RJ, Eck LH, Isbell TR, Klesges LM: Parental influence on food selection in young children and its relationships to childhood obesity. Am J Clin Nutr 1991;53:859-64.

6. Gummeson L, Jonsson I, Conner MT, Svensson E: Assessing factors influencing food choice among 10-16-year-old schoolboys. A pilot study with a stacking box method. J Hum Nutr Dietet 1996;9:219-29.

7. Resnicow K, Reinhard J: What do children know about fat, fiber and cholesterol? A survey of 5116 primary and secondary school students. J Nutr Educ 1991;23:65-71.

8. Lagström H, Jokinen E, Seppänen R, Rönnemaa T, Viikari J, Välimäki I, Venetoklis J, Myyrinmaa A, Niinikoski H, Lapinleimu H, Simell O: Nutrient intakes by young children in a prospective randomized trial of lowsaturated-fat, low-cholesterol diet. The STRIP project. Arch Pediatr Adolesc Med 1997;151:181-8.

9. Lyly M: Ravitsemusneuvonnan vaikutus pikkulasten ruoankäyttöön (Effect of dietary counseling on food consumption of small children). Master thesis (in Finnish). Helsinki, Fin-land 1999.

10. Lapinleimu H, Viikari J, Jokinen E, Salo P, Routi T, Leino A, Rönnemaa T, Seppänen R, Välimäki I, Simell O: Prospective ran-domized trial in 1062 infants of diet low in saturated fat and cholesterol. Lancet 1995:345:471-6.

11. Niinikoski H, Viikari J, Rönnemaa T, Lapinleimu H, Jokinen E, Salo P, Seppänen R, Leino A, Tuominen J, Välimäki I, Simell O: Prospective randomized trial of low-saturated-fat, low-cholesterol diet during the first 3 years of life. The STRIP baby project. Circulation 1996;94: -1386-93.

12. Lagström H: Nutrient intake and food choice during a child-targeted

\section{Conclusions}

In conclusion, this study shows that it is possible to influence children's food choices, especially milk choice, with dietary counseling given via parents. It was only for milk that the extensive parental counseling seemed to have had an effect. There was no difference between groups with respect to the choice of fruit and vegetables. This might be due to the fact that children under school age learn the basics of healthy food habits at home. In the STRIP project the main aim has been to make a healthy diet an important part of the individual's lifestyle, which could possibly in the future reduce mortality from coronary heart disease (10-12).

Also, learning how dietary patterns really develop during infancy and early life is important in order to target primary prevention at the right age group. More precisely, the composition of changes in specific dietary components require to be assessed in childhood.

Further, parental support is needed to implement new eating habits and to make the changed eating patterns permanent, since young children are susceptible to change in their habits. Dietary and possibly other lifestyle habits are strongly influenced by experiences and role models in childhood, suggesting that dietary interventions should probably always target whole families, for example in primary prevention of CHD.

coronary heart disease prevention trial. Doctoral thesis. Studies in social security and health 41. Turku, Finland: Kela, 1999.

13. Lawless H: Sensory development in children: Research in taste and olfaction. J Am Diet As-soc 1985;85: 577-82.

14. Birch LL: Children's food acceptance patterns. Nutrition Today 1996 31:234-40.

15. Koivisto-Hursti UK: Child food choice and the family. Doctoral thesis. Uppsala, Sweden: Uppsala University, 1997.

16. Räsänen $M$, Niinikoski $H$, Keksinen S, Tuominen J, Simell O, Viikari J Rönnemaa T. Nutri-tion knowledge and food intake of seven-year-old children in an atherosclerosis prevention project with onset in infancy: the impact of child-targeted nutrition counselling given to the parents. Eur J Clin Nutr 2001;55:260-267.

17. Anliker JA, Laus MA, Samonds KW, Beal VA: Parental messages and the nutrition aware-ness of preschool children. J Nutr Educ 1990;22:24-9.

18. Birch LL, Johnson SL, Andersen G, Peters JC, Schulte MC: The variability of young chil-dren's energy intake. N Engl J Med 1991;324:232-5.

19. Crockett SJ, Mullis RM, Perry CL: Parent nutrition education: a conceptual model. J School Health 1988;58:53-7.

20. Perry CL, Luepker RV, Murray DM, Kurth C, Mullis RM, Crockett S, Jacobs DR: Parent involvement with children's health promotion: The Minnesota Home Team. Am J Public Health 1988;78:1156-60.

21. Gillespie AH, Achterberg CL: Comparison of family interaction pattern related to food and nutrition. J Am Diet Assoc 1989;89:509-12.

22. Singleton JC, Achterberg CL, Shannon BM: Role of food and nutrition in the health percep-tions of young children. J Am Diet Assoc 1992;92:67-70.

23. Lee RS, Schvaneveldt JD, Sorenson AW: Nutritional Understanding of preschool children taught in the home or a child health development laboratory. Home Econ Res J 1984;13:52-60.

24. Lytle LA, Eldridge AL, Kotz K, Piper J, Williams S, Kalina B: Children's interpretation of nutrition message. J Nutr Educ 1997;29:128-36.

25. Murphy AS, Youatt JP, Hoerr SL, Sawyer CA, Andrews SL: Kindergarten students' food preferences are not consistent with their knowledge of the dietary guidelines. J Am Diet Assoc 1995; 95:219-23.

26. Birch LL. The role of experience in children's food acceptance patterns: J Am Diet Assoc 1987(suppl);87:36-40.

27. Perry CL, Luepker RV, Murray DM, Hearn MD, Halper A, Dubovitz B, Maile MC, Smyth M: Parent involvement with children's health promotion: A one-year follow-up of the Minnesota Home Team. Health Educ Q 1989;16:171-80.

28. Oliveria SA, Ellison RC, Moore LL, Gillman MW, Garrahie EJ, Singer MR Parent-child relationships in nutrient intake: the Framingham Children's Study. Am J Clin Nutr 1992;56:593-8. 